\title{
"Drawing" Conclusions About Perceptions of Ideal Male and Female Body Shapes
}

\author{
Jaime M. Cloud ${ }^{1}$ - Carin Perilloux ${ }^{2}$
}

Published online: 7 May 2015

(C) Springer International Publishing 2015

\begin{abstract}
Preferences for bodily traits (e.g., waist-to-hip ratio; WHR) have been widely documented through the use of stimulus sets (e.g., line drawings, photographs). The purpose of the present study was to explore preferences for bodily traits using a method that does not constrain the range of possible values for each trait. Participants drew a figure depicting the most attractive member of the opposite sex they could imagine and a figure depicting a member of their own sex that they believed members of the opposite sex would find maximally attractive. Participants drew some traits similarly to values identified in previous research (e.g., WHR); however, other traits (e.g., leg-to-body ratio) were drawn differently from values documented through the use of stimulus sets. Additional analyses showed that men were fairly accurate in predicting what women prefer in a man's bodily traits, but women underestimated the ideal WHR and overestimated the ideal bust-to-waist ratio considered by men to be maximally attractive. In contrast to our predictions, participants' morphological trait preferences were independent of their sociosexual orientations. While the unconstrained drawing task
\end{abstract}

This research was presented at the 14th Annual Meeting of the Society for Personality and Social Psychology, New Orleans, LA.

Electronic supplementary material The online version of this article (doi:10.1007/s40806-015-0020-x) contains supplementary material, which is available to authorized users.

Jaime M. Cloud

cloudj@wou.edu

Carin Perilloux

c_p223@txstate.edu

1 Psychological Sciences Department, Western Oregon University, 345 N. Monmouth Avenue, Monmouth, OR, USA

2 Department of Psychology, Texas State University, 601 University Drive, San Marcos, TX, USA produced slightly different results than those obtained through the use of stimulus sets for some traits, its sensitivity to a larger range of potential values renders it a powerful method of exploring morphological trait preferences.

Keywords Attractiveness - Mate preferences - Sex differences · Waist-to-hip ratio - Sociosexual orientation

Preferences for specific morphological traits in a romantic partner have been widely documented (for a review, see Sugiyama 2005). Bodily traits-such as waist-to-hip ratio (WHR), body mass index, and breast size - appear to provide a window to the target's health and reproductive condition (Cloud and Perilloux 2014). Much research has focused on identifying men's and women's mate preferences in light of their consequences for reproductive success; however, the methods employed almost exclusively entail participants choosing the most attractive option from a given stimulus set (e.g., line drawings; Singh 1993; but see Crossley et al. 2012). The purpose of the present study was to explore preferences for various morphological traits using a method that does not constrain the range of possible values for the bodily traits of interest.

Most studies of physical attractiveness require participants to view a set of images that differ on key traits. Preferences for WHR, for example, were first studied using line drawings that varied by weight and WHR (Singh 1993). Within each body weight category-underweight, normal weight, and overweight - were four values of WHR: 0.70, $0.80,0.90$, and 1.00 . This method and those similar to it (e.g., photographic stimuli, digitally manipulated silhouettes) reveal a robust preference for female figures with WHRs that approximate 0.70 (e.g., Furnham et al. 2005; Henss 2000; Kościński 2014), a finding consistent with research 
showing that women with low WHR (i.e., 0.68-0.80) have higher levels of circulating estrogen (Jasieńska et al. 2004; cf. Grillot et al. 2014). Preferences for other estrogendependent traits, such as medium to large breasts (i.e., a bust-to-waist ratio [BWR] of approximately 1.30; Gründl et al. 2009), have also been identified through the use of stimulus sets (e.g., Dixson et al. 2011; Zelazniewicz and Pawlowski 2011).

Similar types of studies have been used to identify the morphological features women find attractive in potential male mates. Muscularity is a trait that has received much empirical attention due to its association with naturally occurring testosterone levels (for a review, see Bhasin 2003). The highest attractiveness ratings are typically given to men with moderate muscularity (Frederick and Haselton 2007), operationalized as a WHR of 0.90 (Dixson et al. 2003; Singh 1995), a waist-to-chest ratio (WCR) of 0.70 (Maisey et al. 1999; Swami and Tovée 2005b), a waist-to-shoulder ratio (WSR) of 0.60 (e.g., Dixson et al. 2003), and a shoulder-to-hip ratio (SHR) of approximately 1.40 (Dijkstra and Buunk 2001; Horvath 1979). This degree of muscularity has been argued to signal fighting ability (Sell et al. 2009) and, in the case of upper body strength, the ability to provide resources (Apicella 2014). Another trait that has been manipulated within stimulus sets is leg length or leg-to-body ratio (LBR), which represents the proportion of an individual's height that is accounted for by the legs (Swami et al. 2006). Average (i.e., approximately 0.50 ) to slightly above-average LBR is considered maximally attractive for male and female figures (e.g., Sorokowski et al. 2011; Swami et al. 2006) possibly because low LBR signals poor cardiovascular health and interruptions in growth during development (Davey Smith et al. 2001; Gunnell et al. 2003).

The findings produced by studies employing stimulus sets are consistent with ultimate explanations of men's and women's evolved mate preferences (Symons 1979); however, the ecological validity of these findings is limited as stimulus sets might fail to accurately represent the range of body shapes that would have been present in ancestral conditions. Some values that were present in ancestral conditions are often excluded from stimulus sets, such as WHR values that reflect pregnancy (i.e., values greater than 1.00) in studies of the ideal female body shape (e.g., Furnham et al. 2005; Henss 2000; Kościński 2014). Furthermore, some features that are present in the modern environment, such as breasts that have been surgically enhanced to extraordinary size or body shapes that reflect morbid obesity (Swami and Tovée 2005a), would not have been present in ancestral environments. In sum, judgments about the attractiveness of bodily traits should be made from the range of values that would have been encountered in ancestral conditions because these are the values that our preference mechanisms evolved to accept as input.

Another criticism that has been leveled against the use of stimulus sets is that having too few figures reduces the precision with which researchers can estimate the most attractive value for a given trait (Crossley et al. 2012; Kościński 2014). Many WHR studies, for example, use Singh's (1993) original line drawings of only four WHR values with 0.70 as the smallest (e.g., Schmalt 2006; Sugiyama 2004). As such, the attractiveness ratings given to the figure with a 0.70 WHR could reflect a preference for 0.70 WHR or could reflect a preference for the smallest WHR available (i.e., a 0.60 WHR might be preferred to a 0.70 WHR if it had been included in the stimulus set).

The present study was designed to remove constraints associated with using stimulus sets by instructing participants to draw the figure they find most physically attractive. Our primary goal was to determine if the values associated with maximum attractiveness on an unconstrained drawing task would be consistent with those previously documented using stimulus sets.

\section{Cross-Sex Preference Perception}

A secondary goal was to assess accuracy in predicting the morphological trait preferences of the opposite sex using the same procedure: participants drew the samesex figure they believed members of the opposite sex would find most physically attractive. Previous research has shown that the traits that elicit jealousy among intrasexual rivals are precisely those that attract members of the opposite sex, such as low WHR in women (Buunk and Dijkstra 2005; Dijkstra and Buunk 2001; Fink et al. 2014) and high SHR in men (Dijkstra and Buunk 2001). Thus, it seems that men and women recognize the traits preferred by the opposite sex; however, both sexes appear to believe that members of the opposite sex prefer more extreme versions of these traits than is actually the case, perhaps reflecting an adaptive motivation to outcompete one's rivals (Hill 2007). For example, when instructed to select a figure that best represents the female body shape desired by men, women consistently select a thinner figure than that which men select as ideal (Bergstrom et al. 2004; Cohn and Adler 1992; Fallon and Rozin 1985; Rozin and Fallon 1988).

Corresponding results in men are less reliable. Some studies have shown that men select a figure that is more muscular than that which women select as ideal (Cohn and Adler 1992; Rozin and Fallon 1988); others indicate that men accurately represent women's morphological trait preferences (Bergstrom et al. 2004; Fallon and Rozin 1985). In line with these results, we predicted that women would underestimate the WHR and overestimate the breast size considered by men to be maximally attractive. Given the lack of consensus in the literature for men's perceptions of women's preferences, we 
did not choose a direction but rather predicted that men would not depart from accuracy in their perceptions of the WHR, WCR, WSR, and SHR considered by women to be maximally attractive. We saw no a priori grounds for predicting that men or women would misperceive the LBR considered by members of the opposite sex to be maximally attractive.

\section{Mating Strategy as a Moderator of Morphological Trait Preferences}

Although many morphological trait preferences are presented as constants (e.g., an unwavering preference for $0.70 \mathrm{WHR}$ ), there is evidence that these preferences are moderated by certain individual differences. One such trait is sociosexual orientation (Gangestad and Simpson 1990), which reflects the degree to which individuals pursue short-term mating strategies. Differences in sociosexual orientation have been shown to influence a variety of men's and women's mate preferences. Men exhibiting an unrestricted sociosexual orientation (i.e., a strong inclination toward casual sexual relationships) express greater interest in viewing a woman's body (relative to her face), which has been argued to exhibit more salient cues of fertility (Confer et al. 2010). Given the relevance of a woman's immediate fertility to the success of an unrestricted mating strategy, it is perhaps unsurprising that preferences for estrogen-dependent traits (e.g., large breasts, low WHR) are exaggerated in men pursuing an unrestricted mating strategy (Singh and Young 1995; Swami et al. 2008; Zelazniewicz and Pawlowski 2011). Sociosexual orientation also predicts women's attraction to traits predictive of healthy gene variants in men. For example, women exhibiting an unrestricted sociosexual orientation report a stronger attraction to men with symmetrical faces (Quist et al. 2012) and men with masculine facial features (e.g., prominent eyebrow ridge; Waynforth et al. 2005). Such women also show a heightened preference for muscular body types (Provost et al. 2006) and masculine gaits (Provost et al. 2008) relative to women with restricted sociosexual orientations.

Thus, a final goal of the present study was to replicate the moderating effect of sociosexual orientation in men's and women's morphological trait preferences. We predicted that men with unrestricted sociosexual orientations would draw opposite-sex figures with larger breasts and smaller WHRs than men with restricted sociosexual orientations. Likewise, we predicted that women with unrestricted sociosexual orientations would draw more muscular (i.e., larger WHR and SHR and smaller WCR and WSR) opposite-sex figures than women with restricted sociosexual orientations. No prediction was made about the moderating effect of sociosexual orientation on men's and women's preferences for LBR.

\section{Method}

\section{Participants}

The sample consisted of 153 undergraduate students who participated in exchange for course credit. Data from participants who did not indicate their sex $(N=3)$ or who identified themselves as non-heterosexual $(N=4)$ were excluded, resulting in a dataset of 61 men (age $M=19.34, \mathrm{SD}=1.38$ ) and 85 women (age $M=19.05, \mathrm{SD}=1.09$ ). Approximately one third of the sample $(32.19 \% ; 17$ men and 30 women) reported being in a committed romantic relationship.

\section{Materials and Procedure}

To reduce demand characteristics, participants were given the impression that they would be randomly assigned to complete two of four possible tasks: (1) draw the outline of a member of the opposite sex that you find maximally attractive; (2) draw the outline of a member of your own sex that you believe members of the opposite sex find maximally attractive; (3) draw the outline of a member of the opposite sex that you believe would make a good friend; or (4) draw the outline of a member of your own sex that you believe would make a good friend. In actuality, participants only completed tasks (1) and (2) in a within-subjects, counterbalanced fashion. For each task, participants received a blank template depicting the head, hands, and feet of a same-sex or opposite-sex individual (see Fig. 1). Participants were then instructed to complete a template in accordance with each task. The instructions informed participants that their drawing did not need to represent a specific person (e.g., significant other) and that the outline of the figure was more important than the inclusion of details or displays of artistic talent. Although participants were allotted an unlimited amount of time, most participants spent approximately 15 min completing both tasks.

Following the completion of both tasks, participants responded to demographic questions to report their sex, age, sexual orientation, and relationship status. The final component of the questionnaire was the revised Sociosexual Orientation Inventory (SOI-R; Penke and Asendorpf 2008) to assess participants' pursuit of short-term mating strategies; higher scores indicate more unrestricted sociosexual orientations. Participation lasted approximately $30 \mathrm{~min}$, after which participants were fully debriefed.

Third-Party Measurements Three undergraduate research assistants, blind to the hypotheses, measured the target traits in participants' drawings using a metric ruler. Figure 2 illustrates the approximate location of the following measurements: chest/bust width (measured across the nipples), waist width (measured at the narrowest point between the chest/bust and the hips), hip width (measured at the widest point between 
Fig. 1 Male (a) and female (b) drawing templates. Participants completed one template under the direction to draw the outline of a hypothetical member of the opposite sex that they find maximally attractive; the other was completed under the direction to draw the outline of a hypothetical same-sex member that they believe members of the opposite sex would find maximally attractive

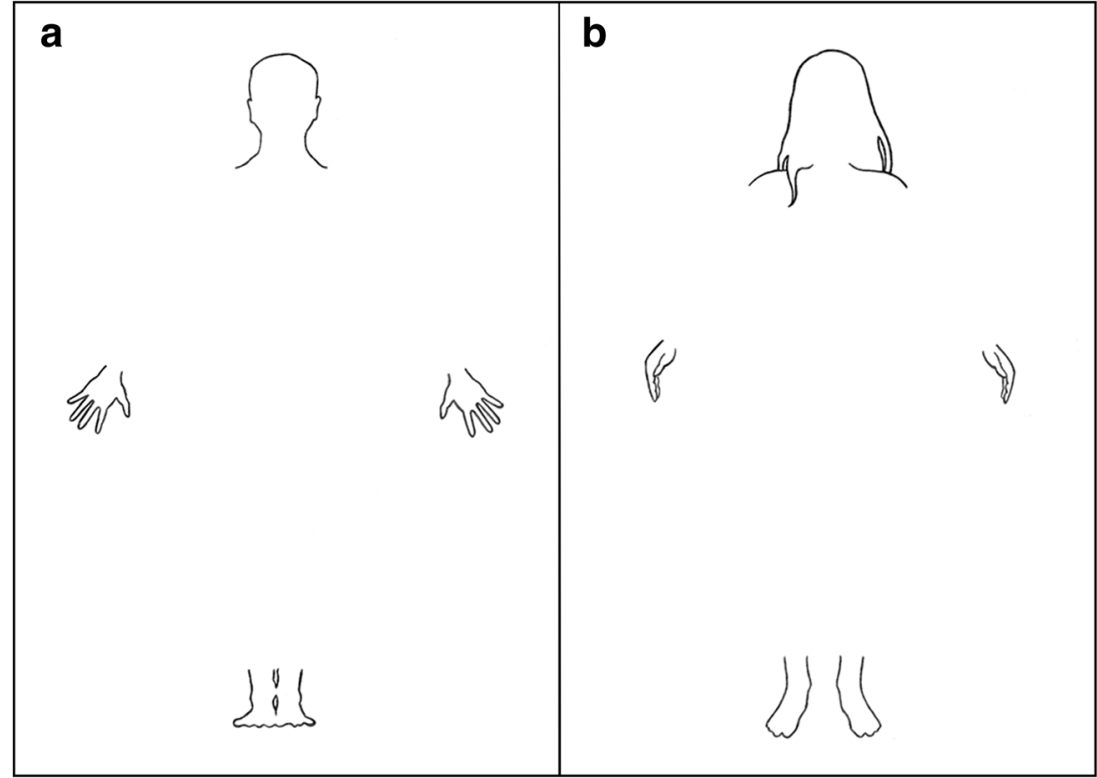

the waist and thighs), and leg length (measured as inseam). Shoulder width (measured at the widest point between the neck and underarm) was also measured in drawings of men. For each trait measurement, the three research assistants' measurements (mean intraclass correlation coefficient $=.89$ ) were averaged, and these composites were used for all calculations and analyses. ${ }^{1}$

\section{Results}

Table 1 presents the mean measurement of each trait drawn by participants on male and female outlines, as well as pertinent ratios. Figures 3 and 4 depict the values we obtained relative to values that have been documented in the literature for comparison. We could not use inferential statistics to compare our results to the specific values identified in previous research, as doing so would underestimate the variability associated with the comparison values. Instead, we plotted the values identified in previous research alongside our obtained data so that the reader can make a visual comparison. Based on a visual inspection of Fig. 3, the WHR and WSR on male outlines drawn by women to depict maximum attractiveness were

\footnotetext{
$\overline{1}$ Women's bust width $\mathrm{ICC}=.91$; women's waist width $\mathrm{ICC}=.82$; women's hip width $=.91$; women's leg length $\mathrm{ICC}=.82$; men's shoulder width $\mathrm{ICC}=.41$; men's chest width $\mathrm{ICC}=.92$; men's waist width $\mathrm{ICC}=.88$; men's hip width $\mathrm{ICC}=.84$; men's leg length $\mathrm{ICC}=.78$. All coefficients were significant at $p<.001$.
}

similar to values obtained in previous research. These drawings, however, did differ from previously documented values in that women drew men with a larger WCR and SHR and a smaller LBR than indicated in previous research. Examining the data displayed in Fig. 4, female outlines drawn by men to depict maximum attractiveness showed a similar BWR as previous studies but a smaller LBR than other studies have indicated. The selection of WHR estimates in Fig. 4 range from 0.70 to 0.73 ; men in the current study drew figures with only slightly larger WHRs $(M=.75)$.

Cross-Sex Preference Perception We ran two comparisons to determine participants' accuracy in predicting the morphological trait preferences of the opposite sex. First, we compared women's drawings of what they believed men find maximally attractive to the drawings actually produced by men depicting the female bodies they preferred most. We then compared men's drawings of what they believed women find maximally attractive to the drawings actually produced by women depicting the male bodies they preferred most. Due to the number of tests, we adopted a lower alpha level of .01. As predicted, women underestimated the WHR that men drew as maximally attractive, $t(144)=-5.79, p<.001$. Women did not overestimate the bust size that men drew as maximally attractive, $t(144)=1.48, p=.14$, but they did overestimate the BWR that men drew as maximally attractive, $t(144)=3.02$, $p=.003$. Women also overestimated the LBR considered by men to be maximally attractive, $t(144)=4.50, p<.001$. There were no significant differences $(p s \geq .13)$ in the traits that men drew to depict what they believed women find maximally attractive and the traits actually drawn by women to be maximally attractive, with the exception of LBR: men 
Fig. 2 Male (a) and female (b) outlines drawn by the same participant. The dashed lines represent the approximate location of where the width or length of each trait was measured

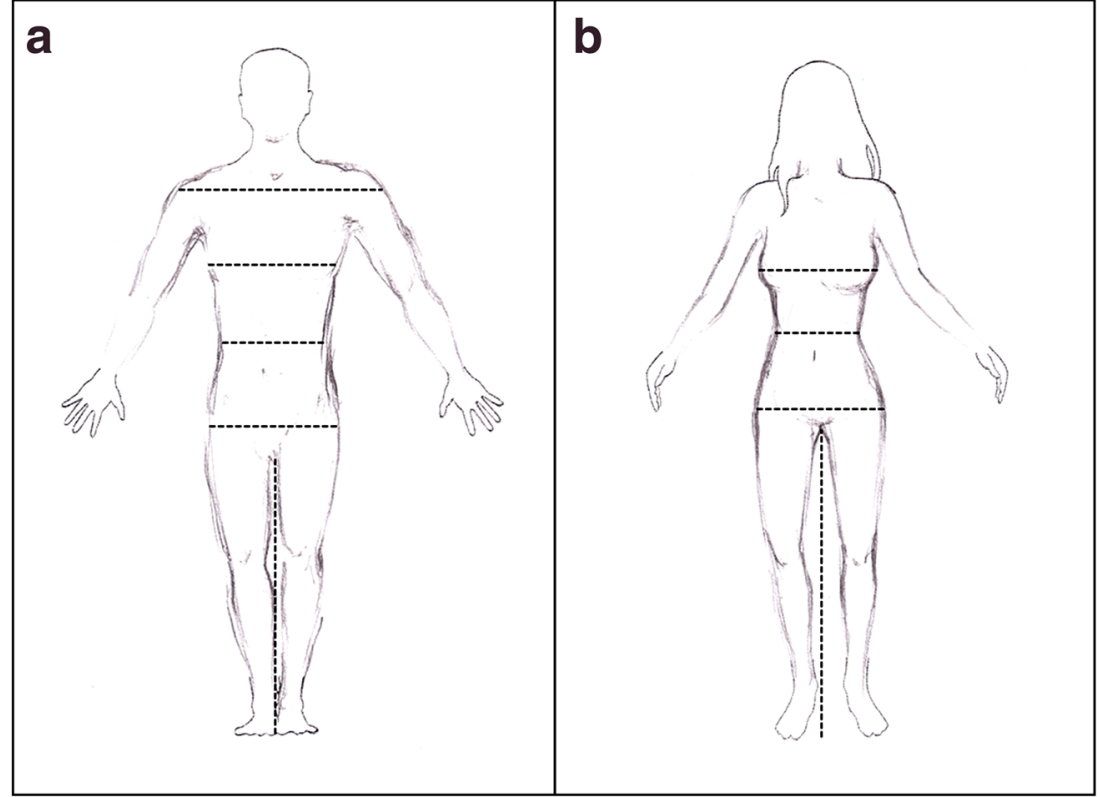

underestimated the LBR considered by women to be maximally attractive, $t(143)-2.67, p=.008$.

\section{Mating Strategy as a Moderator of Trait Preferences To} evaluate whether sociosexual orientation moderates men's and women's morphological trait preferences, we correlated the traits drawn by participants to depict maximum attractiveness in a potential mate with their SOI-R scores. Participants (three women and eight men) who did not complete the SOI-R were omitted from these analyses. Again, due to the number of tests, we adopted a lower alpha level of .01. Although in the predicted direction, men's SOI-R scores were not significantly correlated with the width of the bust men drew in female outlines, $r(53)=.28, p=.04$. In contrast to our prediction, men's SOI-R scores did not significantly correlate with the
WHR men drew in female outlines, $r(53)=-.09, p=.51$, nor did women's SOI-R scores correlate with the WHR, WCR, $\mathrm{WSR}$, or SHR women drew in male outlines ( $p \mathrm{~s} \geq .19)$. Finally, men's SOI-R scores did not correlate with the LBR men drew in female outlines $r(53)=-.08, p=.58$; nor did women's SOI$\mathrm{R}$ scores correlate with the LBR women drew in male outlines $r(81)=-.22, p=.05$.

\section{Discussion}

The present findings corroborate past research showing a preference for WHR of approximately 0.70 in women and 0.90 in men (e.g., Singh 1993) and indicate that these widely documented preferences are unlikely to be an artifact of the use of

Table 1 Traits drawn to depict maximum attractiveness

\begin{tabular}{|c|c|c|c|c|c|c|c|c|}
\hline \multirow[b]{2}{*}{ Trait } & \multicolumn{2}{|c|}{ Women drawing men } & \multicolumn{2}{|c|}{ Men drawing women } & \multicolumn{2}{|c|}{ Men drawing men } & \multicolumn{2}{|c|}{ Women drawing women } \\
\hline & $M$ & SD & $M$ & $\mathrm{SD}$ & $M$ & SD & $M$ & $\mathrm{SD}$ \\
\hline Shoulder width $(\mathrm{cm})$ & 5.52 & 0.76 & - & - & 5.72 & 0.72 & - & - \\
\hline Chest/bust width (cm) & 4.09 & 0.52 & 3.70 & 0.39 & 4.23 & 0.64 & 3.59 & 0.46 \\
\hline Waist width $(\mathrm{cm})$ & 3.40 & 0.41 & 2.88 & 0.43 & 3.47 & 0.44 & 2.56 & 0.42 \\
\hline Hip width (cm) & 3.77 & 0.41 & 3.85 & 0.45 & 3.77 & 0.43 & 3.94 & 0.39 \\
\hline Leg length $(\mathrm{cm})$ & 8.38 & 0.70 & 8.95 & 0.84 & 8.02 & 0.88 & 9.52 & 0.67 \\
\hline WHR & 0.90 & 0.09 & 0.75 & 0.11 & 0.93 & 0.09 & 0.65 & 0.10 \\
\hline WCR & 0.84 & 0.12 & - & - & 0.84 & 0.15 & - & - \\
\hline BWR & - & - & 1.31 & 0.22 & - & - & 1.43 & 0.26 \\
\hline WSR & 0.62 & 0.10 & - & - & 0.61 & 0.09 & - & - \\
\hline SHR & 1.48 & 0.23 & - & - & 1.53 & 0.21 & - & - \\
\hline LBR & 0.43 & 0.04 & 0.43 & 0.04 & 0.41 & 0.04 & 0.46 & 0.03 \\
\hline
\end{tabular}




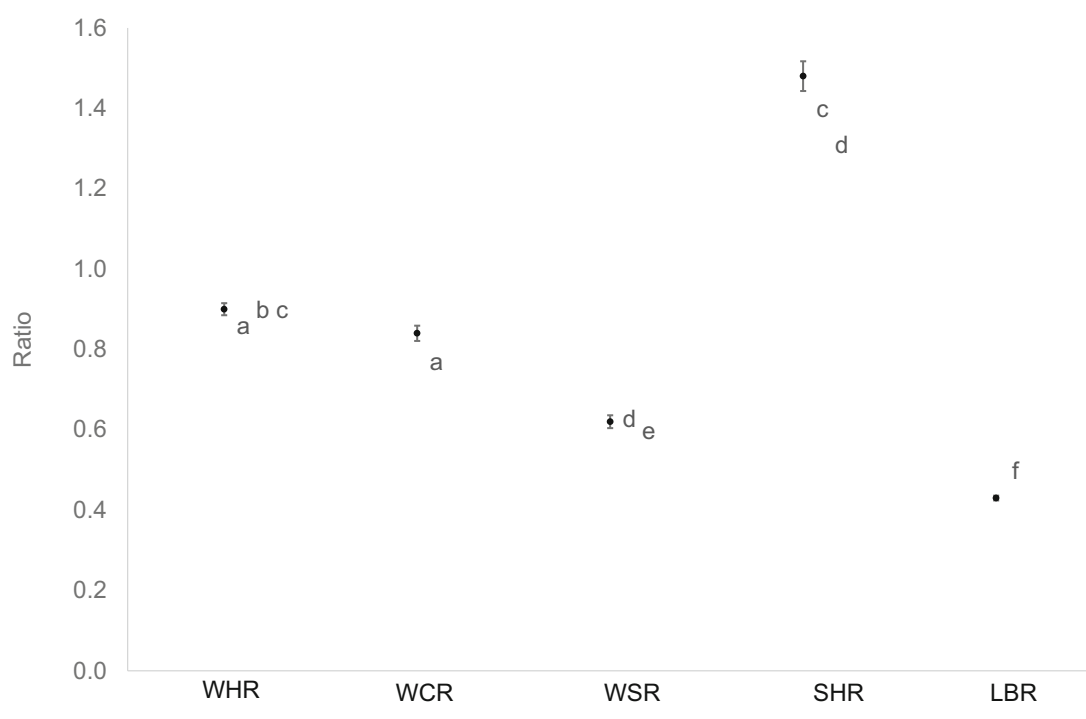

Fig. 3 Ratio values associated with maximum attractiveness for male figures drawn by women in the current study compared to values identified in previous research. Note: Data from the current study are indicated by black dots with $95 \%$ confidence intervals as error bars. Values identified in prior research as indicating highest attractiveness

stimulus sets. The current study replicated patterns found in previous research concerning other morphological trait preferences, with a few small differences from the specific values documented via stimulus sets. The traits that showed the greatest discrepancy (e.g., LBR of 0.43 vs. 0.50; Sorokowski et al. 2011; Swami et al. 2006) tended to be those that have been researched the least; thus, no specific value has yet been corroborated by multiple studies. Another reason for

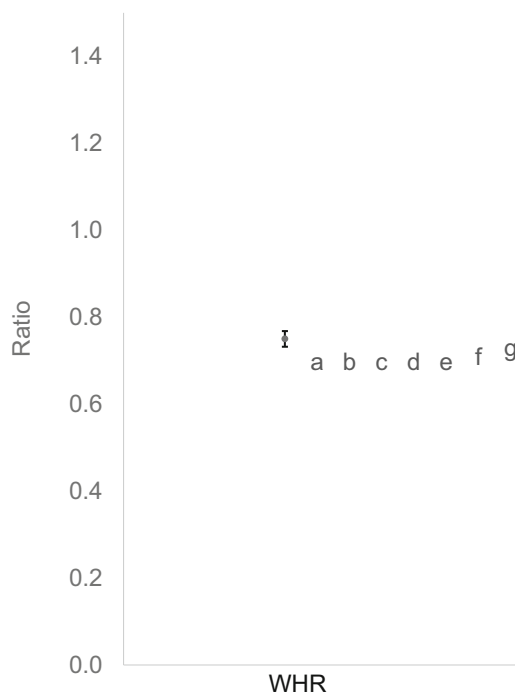

Fig. 4 Ratio values associated with maximum attractiveness for female figures drawn by men in the current study compared to values identified in previous research. Note: Data from the current study are indicated by black dots with $95 \%$ confidence intervals as error bars. Values identified in prior research as indicating highest attractiveness are denoted on the are denoted on the graph by lowercase letters (citations below). WHR waist-to-hip ratio, $W C R$ waist-to-chest ratio, $W S R$ waist-to-shoulder ratio, $S H R$ shoulder-to-hip ratio, $L B R$ leg-to-body ratio. a Crossley et al. 2012; $b$ Singh 1995; $c$ Dijkstra and Buunk 2001; $d$ Horvath 1979; $e$ Dixson et al. 2003; $f$ Swami et al. 2006

discrepancies could be that the most attractive value for a given trait might fall between the discrete intervals typically used in stimulus set research (e.g., WSR of 0.50, 0.55, 0.60, and 0.65; Dixson et al. 2003), a constraint that has been eliminated in the current study.

Our results are similar to those found by Crossley et al. (2012) who instructed participants to design maximally attractive members of the same and opposite sex using an

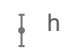

BWR LBR

graph by lowercase letters (citations below). WHR waist-to-hip ratio, $B W R$ bust-to-waist ratio, $L B R$ leg-to-body ratio. a Dijkstra and Buunk 2001; $b$ Singh 1993; c Furnham et al. 2005; $d$ Kościński 2014; $e$ Schmalt 2006; $f$ Henss 2000; $g$ Crossley et al. 2012; $h$ Gründl et al. 2009; $i$ Swami et al. 2006 
interactive $3 \mathrm{D}$ computer program that enabled participants to adjust sliders along 94 independent dimensions of physiology. Their results showed that the ideal WHR was near 0.70 for women ( 0.70 as designed by female participants; 0.73 as designed by male participants) and near 0.90 for men ( 0.86 as designed by female participants; 0.87 as designed by male participants). As in the current study, the values they found to be associated with maximum attractiveness for WCR were higher than those identified through the use of stimulus sets (Maisey et al. 1999; Swami and Tovée 2005b). This may be an artifact of stimulus sets failing to include the full range of potential values, in this case by not including larger values. For example, the largest WCR value in the stimulus sets used by Maisey et al. (1999) and Swami and Tovée (2005b) was 0.90.

The morphological trait values that men believed women would find maximally attractive in a potential mate were similar to those that women considered to be maximally attractive, a finding consistent with previous research documenting men's accuracy with this task using stimulus sets (Bergstrom et al. 2004; Fallon and Rozin 1985). Women were not as accurate in predicting men's preferences, however. As previously documented in relation to thinness (Bergstrom et al. 2004; Cohn and Adler 1992; Fallon and Rozin 1985; Rozin and Fallon 1988), women underestimated the ideal WHR and overestimated the ideal BWR considered by men to be maximally attractive. Through their interactive $3 \mathrm{D}$ program, Crossley et al. (2012) also showed that women overestimated men's ideal BWR. Researchers have argued that this tendency represents an evolved strategy to avoid the costly error of underestimating the competition posed by same-sex competitors (Haselton and Buss 2000; Hill 2007). By this proposal, individuals who overestimated the desirability of intrasexual rivals would have been more motivated to improve or flaunt their own attributes. If this is indeed the case, it is unclear why men did not show a corresponding bias in their estimates of women's preferred levels of muscularity (i.e., WHR, WCR, WSR, and SHR). Perhaps, as one of us (CP) and others have recently suggested, some apparent biases are either not biases or might operate at the level of behavior (including selfreports) rather than biasing beliefs at the cognitive level (McKay and Efferson 2010; Perilloux and Kurzban 2015). If so, it is possible that women's apparent "bias" in reporting that men prefer women with more extreme physiological traits could be an intrasexually motivated method of intimidating other women. These ideas, of course, remain open questions for future research.

Counter to previous research (Provost et al. 2006; Swami et al. 2008), our participants' morphological trait preferences were unrelated to their sociosexual orientation. We considered the possibility of a restricted range problem with regard to SOI-R scores in our sample; however, the SOI-R values of the current study $(M=27.86, \mathrm{SD}=13.42)$ are comparable to those found by other researchers using the same scale
(Swami et al. 2008; Zelazniewicz and Pawlowski 2011). If sociosexual orientation exerts a relatively small effect on men's and women's mate preferences, then the precision with which participants were able to represent their preferences might have fallen within that margin of error.

There are a few limitations of using an unconstrained drawing task that center on accuracy. First is the fact that participants could still choose to draw body shapes that are not representative of the natural range of values found in ancestral environments (e.g., by drawing unnaturally large breasts). The drawings made by our participants, however, do not show such unnatural features and instead confirm the values documented by prior research, as shown in Figs. 3 and 4.

Second, although we provided participants with the head, hands, and feet of the outline as reference points, a second limitation is that participants' degree of artistic talent (or lack thereof) could have prevented their drawings from accurately reflecting their true morphological trait preferences. Third, the templates in this experiment necessitated drawing the male and female outlines as two-dimensional images. Only the width or length of each trait could be measured, but measurements of circumference might have been more ecologically valid. Hip width, for example, fails to capture the protuberance of the buttocks, which has been shown to influence judgments of attractiveness (Marlowe et al. 2005). Even with these potential limitations, it seems that participants were able to draw their ideal body shapes with relative accuracy insofar as many of the values associated with maximum attractiveness in the current study converge with those found through the adjustment of 3D computer-generated images (Crossley et al. 2012) and previous research with stimulus sets (as shown in Figs. 3 and 4). In addition, the unconstrained drawing task has the advantage of not presenting participants with a starting figure from which to make their adjustments; thus, there is no possibility that participants' morphological trait preferences were anchored by arbitrary starting values (Tversky and Kahneman 1974).

Now that we have shown that an unconstrained drawing procedure can be used effectively to elicit participants' preferences for bodily traits, future studies could use a similar procedure to examine facial attractiveness or bodily preferences for other types of target individuals. For example, participants could be asked to draw bodies for the conditions we did not use in the present study: same-sex friends and opposite-sex friends. Based on research showing sex differences in the perceived benefits of opposite-sex friendships, we would predict that women would draw muscular men who can more easily provide protection (Bleske and Buss 2000; Bleske-Rechek and Buss 2001) and that men would draw female figures similar to those they drew to depict maximum attractiveness, given that men tend to value potential sexual access in their female friends (Bleske and Buss 2000; BleskeRechek and Buss 2001). 
The present study utilized a novel method to replicate previously documented preferences for specific morphological traits (e.g., WHR). The unconstrained drawing task (and those similar to it: Crossley et al. 2012) is a valuable addition to psychologists' methodological toolbox. The spontaneous generation of preferences with values similar to those obtained through the use of stimulus sets can provide strong convergent evidence for many facets of our evolved mating psychology.

Acknowledgments The authors thank Zachary L. Simmons and Mark D. Cloud for providing helpful feedback on drafts of this manuscript

\section{References}

Apicella, C. L. (2014). Upper-body strength predicts hunting reputations and reproductive success in Hadza hunter-gatherers. Evolution and Human Behavior, 35, 508-518.

Bergstrom, R. L., Neighbors, C., \& Lewis, M. A. (2004). Do men find "bony" women attractive? Consequences of misperceiving opposite sex perceptions of attractive body image. Body Image, 1, 183-191.

Bhasin, S. (2003). Regulation of body composition by androgens. Journal of Endocrinological Investigation, 26, 814-822.

Bleske, A. L., \& Buss, D. M. (2000). Can men and women just be friends? Personal Relationships, 7, 131-151.

Bleske-Rechek, A. L., \& Buss, D. M. (2001). Opposite-sex friendship: sex differences and similarities in initiation, selection, and dissolution. Personality and Social Psychology Bulletin, 27, 1310-1323.

Buunk, B. P., \& Dijkstra, P. (2005). A narrow waist versus broad shoulders: sex and age differences in the jealousy-evoking characteristics of a rival's body build. Personality and Individual Differences, 39, 379-389.

Cloud, J. M., \& Perilloux, C. (2014). Bodily attractiveness as a window to women's fertility and reproductive value. In V. A. WeekesShackelford \& T. K. Shackelford (Eds.), Evolutionary perspectives on human sexual psychology and behavior (pp. 135-152). New York: Springer.

Cohn, L. D., \& Adler, N. E. (1992). Female and male perceptions of ideal body shapes: distorted views among Caucasian college students. Psychology of Women Quarterly, 16, 69-79.

Confer, J. C., Perilloux, C., \& Buss, D. M. (2010). More than just a pretty face: men's priority shifts toward bodily attractiveness in short-term versus long-term mating contexts. Evolution and Human Behavior, 31, 348-353.

Crossley, K. L., Cornelissen, P. L., \& Tovée, M. J. (2012). What is an attractive body? Using an interactive 3D program to create the ideal body for you and your partner. PLoS ONE, 7, 1-11.

Davey Smith, G., Greenwood, R., Gunnell, D., Sweetnam, P., Yarnell, J., \& Elwood, P. (2001). Leg length, insulin resistance, and coronary heart disease risk: the Caerphilly Study. Journal of Epidemiology and Community Health, 55, 867-872.

Dijkstra, P., \& Buunk, B. P. (2001). Sex differences in the jealousyevoking nature of a rival's body build. Evolution and Human Behavior, 22, 335-341.

Dixson, A. F., Halliwell, G., East, R., Wignarajah, P., \& Anderson, M. J. (2003). Masculine somatotype and hirsuteness as determinants of sexual attractiveness to women. Archives of Sexual Behavior, 32, 29-39.

Dixson, B. J., Grimshaw, G. M., Linklater, W. L., \& Dixson, A. F. (2011). Eye tracking of men's preferences for female breast size and areola pigmentation. Archives of Sexual Behavior, 40, 51-58.
Fallon, A. E., \& Rozin, P. (1985). Sex differences in perceptions of desirable body shape. Journal of Abnormal Psychology, 94, 102-105.

Fink, B., Klappauf, D., Brewer, G., \& Shackelford, T. K. (2014). Female physical characteristics and intra-sexual competition in women. Personality and Individual Differences, 58, 138-141.

Frederick, D. A., \& Haselton, M. G. (2007). Why is muscularity sexy? Tests of the fitness indicator hypothesis. Personality and Social Psychology Bulletin, 33, 1167-1183.

Furnham, A., Petrides, K. V., \& Constantinides, A. (2005). The effects of body mass index and waist-to-hip ratio of ratings of female attractiveness, fecundity, and health. Personality and Individual Differences, 38, 1823-1834.

Gangestad, S. W., \& Simpson, J. A. (1990). Toward an evolutionary history of female sociosexual variation. Journal of Personality, 58, 69-96.

Grillot, R. L., Simmons, Z. L., Lukaszewski, A. W., \& Roney, J. R. (2014). Hormonal and morphological predictors of women's body attractiveness. Evolution and Human Behavior, 35, 176-183.

Gründl, M., Eisenmann-Klein, M., \& Prantl, L. (2009). Quantifying female bodily attractiveness by a statistical analysis of body measurements. Plastic and Reconstructive Surgery, 123, 1064-1071.

Gunnell, D., Whitley, E., Upton, M. N., McConnachie, A., Davey Smith, G., \& Watt, G. C. M. (2003). Associations of height, leg length and lung function with cardiovascular risk factors in the Midspan Family Study. Journal of Epidemiology and Community Health, 57, 141146.

Haselton, M. G., \& Buss, D. M. (2000). Error management theory: a new perspective on biases in cross-sex mind reading. Journal of Personality and Social Psychology, 78, 81-91.

Henss, R. (2000). Waist-to-hip ratio and female attractiveness. Evidence from photographic stimuli and methodological considerations. Personality and Individual Differences, 28, 501-513.

Hill, S. E. (2007). Overestimation bias in mate competition. Evolution and Human Behavior, 28, 118-123.

Horvath, T. (1979). Correlates of physical beauty in men and women. Social Behavior and Personality, 7, 145-151.

Jasieńska, G., Ziomkiewicz, A., Ellison, P. T., Lipson, S. F., \& Thune, I. (2004). Large breasts and narrow waists indicate high reproductive potential in women. Proceedings of the Royal Society of London B, 271, 1213-1217.

Kościński, K. (2014). Assessment of waist-to-hip ratio attractiveness in women: an anthropometric analysis of digital silhouettes. Archives of Sexual Behavior, 43, 989-997.

Maisey, D. S., Vale, E. L., Cornelissen, P. L., \& Tovée, M. J. (1999). Characteristics of male attractiveness for women. Lancet, 353, 1500.

Marlowe, F., Apicella, C., \& Reed, D. (2005). Men's preferences for women's profile waist-to-hip ratio in two societies. Evolution and Human Behavior, 26, 458-468.

McKay, R., \& Efferson, C. (2010). The subtleties of error management. Evolution and Human Behavior, 21,309-319.

Penke, L., \& Asendorpf, J. B. (2008). Beyond global sociosexual orientations: a more differentiated look at sociosexuality and its effects on courtship and romantic relationships. Journal of Personality and Social Psychology, 95, 1113-1135.

Perilloux, C., \& Kurzban, R. (2015). Do men over-perceive women's sexual interest? Psychological Science, 26, 70-77.

Provost, M. P., Kormos, C., Kosakoski, G., \& Quinsey, V. L. (2006). Sociosexuality in women and preference for facial masculinization and somatotype in men. Archives of Sexual Behavior, 35, 305-312.

Provost, M. P., Troje, N. F., \& Quinsey, V. L. (2008). Short-term mating strategies and attraction to masculinity in point-light walkers. Evolution and Human Behavior, 29, 65-69.

Quist, M. C., Watkins, C. D., Smith, F. G., Little, A. C., Debruine, L. M., \& Jones, B. C. (2012). Sociosexuality predicts women's preferences for symmetry in men's faces. Archives of Sexual Behavior, 41, $1415-1421$. 
Rozin, P., \& Fallon, A. (1988). Body image, attitudes to weight, and misperceptions of figure preferences of the opposite sex: a comparison of men and women in two generations. Journal of Abnormal Psychology, 97, 342-345.

Schmalt, H. D. (2006). Waist-to-hip ratio and female physical attractiveness: the moderating role of power motivation and the mating context. Personality and Individual Differences, 41, 455-465.

Sell, A., Cosmides, L., Tooby, J., Sznycer, D., von Rueden, C., \& Gurven, M. (2009). Human adaptations for the visual assessment of strength and fighting ability from the body and face. Proceedings of the Royal Society B: Biological Sciences, 276, 575-584.

Singh, D. (1993). Adaptive significance of female physical attractiveness: role of waist-to-hip ratio. Journal of Personality and Social Psychology, 65, 293-307.

Singh, D. (1995). Female judgment of male attractiveness and desirability for relationships: role of waist-to-hip ratio and financial status. Journal of Personality and Social Psychology, 69, 10891101.

Singh, D., \& Young, R. K. (1995). Body weight, waist-to-hip ratio, breasts, and hips: role in judgments of female attractiveness and desirability for relationships. Ethology and Sociobiology, 16, 483-507.

Sorokowski, P., Szmajke, A., Sorokowska, A., Cunen, M. B., Fabrykant, M., Zarafshani, K., et al. (2011). Attractiveness of leg length: report from 27 nations. Journal of Cross-Cultural Psychology, 42, 131139.
Sugiyama, L. S. (2004). Is beauty in the context-sensitive adaptations of the beholder? Shiwiar use of waist-to-hip ratio in assessments of female mate value. Evolution and Human Behavior, 25, 51-62.

Sugiyama, L. S. (2005). Physical attractiveness in adaptationist perspective. In D. M. Buss (Ed.), The handbook of evolutionary psychology (pp. 292-343). Hoboken: Wiley.

Swami, V., \& Tovée, M. J. (2005a). Female physical attractiveness in Britain and Malaysia: a cross-cultural study. Body Image, 2, 115-128.

Swami, V., \& Tovée, M. J. (2005b). Male physical attractiveness in Britain and Malaysia: a cross-cultural study. Body Image, 2, 383-393.

Swami, V., Einon, D., \& Furnham, A. (2006). The leg-to-body ratio as a human aesthetic criterion. Body Image, 3, 317-323.

Swami, V., Miller, R., Furnham, A., Penke, L., \& Tovée, M. J. (2008). The influence of men's sexual strategies on perceptions of women's bodily attractiveness, health and fertility. Personality and Individual Differences, 44, 98-107.

Symons, D. (1979). The evolution of human sexuality. New York: Oxford University Press.

Tversky, A., \& Kahneman, D. (1974). Judgment under uncertainty: heuristics and biases. Science, 185, 1124-1131.

Waynforth, D., Delwadia, S., \& Camm, M. (2005). The influence of women's mating strategies on preference for masculine facial architecture. Evolution and Human Behavior, 26, 409-416.

Zelazniewicz, A. M., \& Pawlowski, B. (2011). Female breast size attractiveness for men as a function of sociosexual orientation (restricted vs. unrestricted). Archives of Sexual Behavior, 40, 1129-1135. 